\title{
Relaxant Effects of Carbon Monoxide Compared with Nitric Oxide in Pulmonary and Systemic Vessels of Newborn Piglets
}

\author{
EDUARDO VILLAMOR, FRANCISCO PÉREZ-VIZCAÍNO, ANGEL L. COGOLLUDO, JESÚS \\ CONDE-OVIEDO, FRANCISCO ZARAGOZÁ-ARNÁEZ, J. GUSTAVO LÓPEZ-LÓPEZ, AND \\ JUAN TAMARGO
}

Department of Pediatrics, University Hospital Maastricht, Research Institute Growth and Development, Maastricht University, 6202 AZ Maastricht, The Netherlands [E.V.]; and Department of Pharmacology, Institute of Pharmacology and Toxicology (CSIC), School of Medicine, Universidad Complutense, 28040 Madrid, Spain [F.P.-V., A.L.C., J.C-O., F.Z.-A. J.G.L.-L., J.T.]

\begin{abstract}
Nitric oxide (NO) has been implicated in a number of diverse physiologic processes, including regulation of vascular tone. Carbon monoxide (CO) is another endogenously generated diatomic gas that may play an important physiologic role in vascular smooth muscle homeostasis. The purpose of this study was to compare the responses to exogenous $\mathrm{NO}$ and $\mathrm{CO}$ in isolated vessels (pulmonary arteries, pulmonary veins, and mesenteric arteries) from 12- to 24-h-old and 2-wk-old piglets. Vessels precontracted with the thromboxane $\mathrm{A}_{2}$ mimetic U46619 $\left(10^{-7} \mathrm{M}\right)$ relaxed in response to $\mathrm{CO}\left(2 \times 10^{-6}\right.$ to $\left.2 \times 10^{-4} \mathrm{M}\right)$ and NO $\left(2 \times 10^{-9}\right.$ to $\left.2 \times 10^{-7} \mathrm{M}\right)$; these effects were not affected by endothelium removal but were completely abolished by the soluble guanylate cyclase inhibitor ODQ $\left(10^{-5} \mathrm{M}\right)$. In pulmonary arteries, the maximal relaxation to NO increased with postnatal age from $33 \pm 4 \%$ of the precontraction value to $56 \pm$ $5 \%$, in 12- to 24 -h-old and 2-week-old piglets, respectively $(p<$ $0.01)$, but the response to $\mathrm{CO}$ decreased from $25 \pm 3 \%$ to $12 \pm$ $1 \%$, respectively $(p<0.01)$. The maximal response to CO was greater in pulmonary veins than in pulmonary or mesenteric arteries for both age groups $(p<0.01)$. Vasorelaxation induced by endogenous NO (stimulated by acetylcholine) was also greater in pulmonary veins when compared with pulmonary arteries and increased with postnatal age in both vessels. In contrast, no age-related differences were observed in the vasorelaxation induced by the cGMP analog 8-bromo cGMP in pulmonary arteries. When the response to $\mathrm{NO}$ was analyzed under three different extracellular $\mathrm{O}_{2}$ concentrations $\left(\mathrm{P}_{2} 4.51 \pm 0.03\right.$,
\end{abstract}

\section{ABSTRACT}

$19.32 \pm 0.17$, and $86 \pm 0.62, \mathrm{kPa})$, no significant differences were found. However, in the presence of superoxide dismutase $(100 \mathrm{U} / \mathrm{mL})$. the response to $\mathrm{CO}$ remained unchanged, and the response to $\mathrm{NO}$ improved in pulmonary arteries from 2-week-old but not from newborn piglets. In conclusion, both $\mathrm{NO}$ and $\mathrm{CO}$ relaxed neonatal vessels through soluble guanylate cyclase activation. However, when compared with $\mathrm{NO}, \mathrm{CO}$ exhibited a poor vasorelaxant activity. Pulmonary vasorelaxation induced by NO increased with postnatal age, whereas that induced by $\mathrm{CO}$ decreased. Changes in extracellular oxygen concentration did not alter the pulmonary vascular response to NO. However, the presence of superoxide dismutase improved the response to NO, indicating that oxidant activity limits the vasorelaxant response to NO but not to CO. (Pediatr Res 48: 546-553, 2000)

Abbreviations
NO, nitric oxide
CO, carbon monoxide
sGC, soluble guanylate cyclase
HO, heme oxygenase
SOD, superoxide dismutase
U46619, 9,11-dideoxy-11 $\alpha, 9 \alpha$-epoxymethano-prostaglandin
$\mathrm{F}_{2 \alpha}$ (thromboxane $\mathrm{A}_{2}$ analog)
L-NAME, $N^{\omega}$-nitro-L-arginine methyl ester
ODQ, $1 \mathrm{H}-[1,2,4]$ oxadiazolo[4,3-a]quinoxalin-1-one (sGC
inhibitor)

$\mathrm{NO}$ is known to be involved in the regulation of multiple physiologic processes, including the regulation of pulmonary

Received October 19, 1999; accepted March 5, 2000.

Correspondence: E. Villamor, M.D., Department of Pediatrics, University Hospital Maastricht, P. Debyelaan 25, P.O. Box 5800, 6202 AZ Maastricht, The Netherlands.

Supported by SAF 99/0069 and CAM 08.4/0019/1998 grants. F. Pérez-Vizcaíno and A.L. Cogolludo are supported by grants from the Comunidad Autónoma de Madrid. vascular tone (1). On the other hand, another diatomic gas, $\mathrm{CO}$, traditionally considered as a toxic pollutant, poisons by binding to the iron-containing heme group found in $\mathrm{Hb}$ and other enzymes (2). Recently, evidence is accumulating that CO can be also a physiologic endogenous regulator $(2,3)$. CO appears to mimic many of the actions of NO, including smooth muscle relaxation and inhibition of platelet aggregation (4), which are mainly mediated through the activation of $\mathrm{sGC}(5)$. 
$\mathrm{CO}$ is produced endogenously by two sources, i.e. enzymatic peroxidation of microsomal lipids and heme destruction catalyzed by $\mathrm{HO}(2,3)$. HOs are rate-limiting enzymes that catalyze the conversion of heme into $\mathrm{CO}$, iron, and biliverdin (3). Two distinct forms of $\mathrm{HO}$ have been characterized, including an inducible HO-1 and a constitutively expressed HO-2 (3). HO-2 has been localized in several tissues, including endothelial cells and adventitial nerves of blood vessels (6). In contrast, HO-1 is scarcely expressed under basal conditions, but it is induced widespread after several types of stressful stimuli, including hypoxia, endotoxins, and ischemia-reperfusion (7, 8). Furthermore, a protective role of HO-1 in several inflammatory conditions has been suggested $(3,9)$.

The ability of $\mathrm{CO}$ to induce vasorelaxation has long been known (10). CO-induced vasodilation has been described in many vascular beds from several species (11-13). However, it is not a universal finding (12), and the sensitivity of the different vessels to $\mathrm{CO}$ is variable (11-13). A vasoregulatory role for endogenous $\mathrm{CO}$ produced by constitutive $\mathrm{HO}-2$ has been postulated in the maintenance of sinusoidal tone in the perfused rat liver (14) and the vascular tone of porcine distal pulmonary arteries (6). Additionally, endogenously released $\mathrm{CO}$ as a consequence of HO-1 induction participated in the regulation of vascular contractility in rat aorta (15) and fetal lamb ductus arteriosus (16). An interaction between $\mathrm{CO}$ and NO may also significantly contribute to the fine-regulation of vascular tone $(3,17)$.

At birth, important structural and functional changes are produced in the pulmonary circulation to replace the placenta for gas exchange (18). This transformation is not limited to the first moments of extrauterine life, but it extends during the subsequent weeks or even months $(18,19)$. The mechanisms regulating birth-related changes in pulmonary circulation are incompletely understood, and numerous vasoactive factors are involved $(1,20)$. As mentioned above, a possible role for $\mathrm{CO}$ has been considered in the control of ductus arteriosus tone (16) but not in pulmonary or other vessels during the perinatal period. However, in the newborn period, the substrate for $\mathrm{CO}$ production, heme, is readily available, and increased $\mathrm{HO}$ activity, and consequently, an increased $\mathrm{CO}$ production, has been described in newborns compared with adults (21). In fact, the pulmonary excretion rate of $\mathrm{CO}$ and end-tidal breath $\mathrm{CO}$ have been proposed as methods to estimate bilirubin production (21). The possible physiologic role of this increased production of $\mathrm{CO}$ remains unknown.

Unfortunately, to the best of our knowledge, neither exogenous $\mathrm{CO}$-induced vasodilation nor the role of endogenous $\mathrm{CO}$ in vascular tone has been studied in vessels from newborn animals. We hypothesized that if CO plays a role in the control of neonatal vascular tone, exogenous $\mathrm{CO}$ should present the ability to relax neonatal vessels. In the present study, we have, therefore, examined the ability and the mechanisms of $\mathrm{CO}$ to induce vasorelaxation in pulmonary arteries, pulmonary veins, and mesenteric arteries from 12- to 24-h-old and 2-week-old piglets. In addition, we compared $\mathrm{CO}$ - to NO-induced vasorelaxation and studied the response under different oxygen concentrations. The effects of superoxide anions produced within the tissue in modulating the response to $\mathrm{CO}$ and $\mathrm{NO}$ were also evaluated.

\section{METHODS}

Tissue preparation. Male neonatal piglets aged 12-24 h $(n=9)$ and $2 \mathrm{wk}(n=20)$, obtained from a local farm, were killed by exsanguination after being anesthetized with sodium pentobarbitone $(100 \mathrm{mg} / \mathrm{kg})$. These procedures were approved by the Complutense University Animal Care and Use Committee. The lungs and mesenteric beds were rapidly immersed in cold $\left(4^{\circ} \mathrm{C}\right) \mathrm{Krebs}$ solution (composition in $\mathrm{mM}$ : $\mathrm{NaCl} 118$, $\mathrm{KCl}$ 4.75, $\mathrm{NaHCO}_{3} 25, \mathrm{MgSO}_{4} 1.2, \mathrm{CaCl}_{2} 2.0, \mathrm{KH}_{2} \mathrm{PO}_{4} 1.2$, and glucose 11). Pulmonary arteries and veins (third branch, internal diameter, $0.5-2 \mathrm{~mm}$ ) and mesenteric arteries (internal diameter, 1-2 mm) were carefully dissected free of surrounding tissue and cut into rings of $2-3 \mathrm{~mm}$ of length under a dissection microscope (22-24). Except as otherwise stated, the endothelium of the vessels was removed by gently rubbing the intimal surface of the rings with a metal rod, and the lack of functional endothelium was further confirmed by the failure of acetylcholine to relax vessels previously contracted by noradrenaline $\left(10^{-5} \mathrm{M}\right)$. Two L-shaped stainless-steel wires were inserted into the arterial lumen, and the rings were introduced into Allhin organ chambers filled with Krebs solution at $37^{\circ} \mathrm{C}$, gassed with $95 \% \mathrm{O}_{2} / 5 \% \mathrm{CO}_{2}$. One wire was attached to the chamber and the other to an isometric force-displacement transducer coupled to a signal amplifier (model PRE 206-4, Cibertec, Madrid) and connected to a Hewlett Packard computer via an analog to digital interface. Contractile tension was recorded by an REGXPC computer program (Cibertec, Madrid), as previously described (22-24). The rings were initially stretched to a resting tension of $0.3 \mathrm{~g}$ (pulmonary arteries of 12- to 24-h-old animals), $0.5 \mathrm{~g}$ (pulmonary arteries of 2-wk-old animals, pulmonary veins of both groups), $1 \mathrm{~g}$ (mesenteric arteries of 12- to 24-h-old animals), or $2 \mathrm{~g}$ (mesenteric arteries of 2-wk-old animals) and allowed to equilibrate for 60-90 $\mathrm{min}$. During this period, tissues were restretched and washed every 30 min with warm Krebs solution.

Experimental protocols. After equilibration, the rings were precontracted with the thromboxane $A_{2}$ mimetic U46619 $\left(10^{-7}\right.$ M). In previous experiments, we demonstrated that this concentration produces approximately $80 \%$ of the maximal U46619-induced contraction in piglet pulmonary vessels (22, 23). When the contractile response reached a stable tension, concentration-response curves to $\mathrm{CO}$ and $\mathrm{NO}$ were conducted by addition of increasing volumes of Krebs solution saturated with $\mathrm{CO}$ or NO. To prepare these solutions, two vials containing $20 \mathrm{~mL}$ of Krebs solution were initially bubbled with $\mathrm{N}_{2}$ for $10 \mathrm{~min}$ and then continuously bubbled with NO (450 ppm) or $\mathrm{CO}$ (purity $>99 \%$ ). Continuous bubbling of the $20-\mathrm{mL}$ Krebs solution vial was started at least $5 \mathrm{~min}$ before the addition of the first dose of $\mathrm{CO}$ or $\mathrm{NO}$ and maintained during the rest of the experiment. The concentrations of $\mathrm{NO}$ and $\mathrm{CO}$ in the saturated solution were estimated from the solubility of $\mathrm{CO}$ and $\mathrm{NO}$ in water at $25^{\circ} \mathrm{C}$ and $1 \mathrm{~atm}$ of pressure $\left(9.687 \times 10^{-4} \mathrm{M}\right.$ and $1.931 \times 10^{-3} \mathrm{M}$, respectively). Actual NO concentrations of Krebs solution saturated with $450 \mathrm{ppm}$ of $\mathrm{NO}$ were measured 
using a selective NO electrode (ISO-NO), which was calibrated using the titration method (i.e. $\mathrm{NO}_{2} \mathrm{Na}$ in the presence of $\mathrm{H}_{2} \mathrm{SO}_{4}$ and $\mathrm{KI}$ ) according to the manufacturer (WPI Inc., Sarasota, FL, U.S.A.). The measured values in four independent determinations $\left(8.9 \pm 0.5 \times 10^{-7} \mathrm{M}\right)$ were in good agreement with those calculated from the solubility of $\mathrm{NO}$ $\left(8.6 \times 10^{-7} \mathrm{M}\right)$ considering the dilution factor $(450 \mathrm{ppm})$. The use of NO at $450 \mathrm{ppm}$ instead of pure NO has the advantage that there is no need to further dilute the saturated solution and that the half-life of NO in solution is higher at lower concentrations (25). We assumed that the loss of added $\mathrm{CO}$ or NO from the Krebs solution at the time of measuring relaxation was negligible. Because this assumption was not strictly correct, actual concentrations of $\mathrm{CO}$ or $\mathrm{NO}$ in the organ chamber might be somewhat lower than estimated (11).

To evaluate the role of endothelium in the vascular response to $\mathrm{CO}$ and $\mathrm{NO}$, some experiments were performed in endothelium-intact pulmonary arteries. Additionally, the role of sGC stimulation in CO- and NO-induced vasorelaxation was analyzed using the specific inhibitor of this enzyme, ODQ $\left(10^{-5}\right.$ M; (26). Finally, to evaluate whether superoxide anions produced within the tissue modulate the response to $\mathrm{CO}$ and $\mathrm{NO}$, some experiments were performed in the presence of the superoxide scavenger SOD $(100 \mathrm{U} / \mathrm{mL})$. Both ODQ and SOD were added after U46619-induced contractions reached steadystate and $15 \mathrm{~min}$ before the concentration-response curve to $\mathrm{CO}$ or NO.

In another group of experiments, the vascular effects of NO in pulmonary arteries were tested under different $\mathrm{O}_{2}$ conditions. For that purpose, the organ chambers were bubbled with $21 \% \mathrm{O}_{2} / 5 \% \mathrm{CO}_{2} / 74 \% \mathrm{~N}_{2}, 95 \% \mathrm{~N}_{2} / 5 \% \mathrm{CO}_{2}$, or $95 \% \mathrm{O}_{2} / 5 \%$ $\mathrm{CO}_{2}$. The $\mathrm{PO}_{2}$ values were measured by a blood gas analyzer (BGA electrolyte, Instrumentation Laboratory Inc., Lexington, MA, U.S.A.). Bubbling with the new gas mixture was started 15 min before the addition of U46619 and maintained for the rest of the experiment.

Additionally, concentration-response curves to acetylcholine $\left(10^{-8}\right.$ to $\left.10^{-5} \mathrm{M}\right)$ were performed in endothelium-intact vessels in the absence or in the presence of the NO synthase inhibitor L-NAME $\left(10^{-4} \mathrm{M}\right)$. In these experiments, the vessels were exposed to L-NAME for $20 \mathrm{~min}$ before the concentrationresponse curves were started. Finally, concentration-response curves to the cell membrane-permeable analog of cGMP, 8-bromo cGMP $\left(10^{-5}\right.$ to $\left.5 \times 10^{-4} \mathrm{M}\right)$, were also performed.

Drugs. The following drugs were used: acetylcholine, LNAME, U46619, SOD (from bovine erythrocytes), 8-bromocGMP (Sigma Chemical Co., Alcobendas, Spain), ODQ (Tocris Cookson Ltd, Bristol, U.K.), NO (450 ppm, Air liquid, Madrid, Spain), and CO (premier grade $>99 \%$ purity, Carburos Metálicos, Barcelona, Spain). All the solid drugs were dissolved initially in distilled deionized water (except ODQ, which was dissolved in DMSO) to prepare a $10^{-2}, 10^{-3}$, or $10^{-4} \mathrm{M}$ stock solution, and further dilutions were made in Krebs. Preparation of CO- and NO-saturated solutions has been explained above.

Statistical analysis. Results are expressed as means \pm SEM of measurements in $n$ arteries. In each protocol, the vessels were obtained from at least four different animals, and a maximum of two vessels per animal was studied. The contractile responses were expressed as absolute values (milligrams), and the relaxant responses as a percentage of the precontractile tone. Statistically significant differences were calculated by means of a one-way ANOVA followed by a Newman-Keuls test. The level of $p<0.05$ was considered statistically significant.

\section{RESULTS}

U46619 $\left(10^{-7} \mathrm{M}\right)$ induced sustained contractile responses in all vessels studied (Table 1). The responses were significantly greater in pulmonary veins and mesenteric arteries than in pulmonary arteries and in vessels from 2-wk-old than from 12to 24-h-old animals.

Both CO $\left(2 \times 10^{-6}\right.$ to $\left.2 \times 10^{-4} \mathrm{M}\right)$ and $\mathrm{NO}\left(2 \times 10^{-9}\right.$ to $\left.2 \times 10^{-7} \mathrm{M}\right)$ caused concentration-dependent relaxation of U46619-prestimulated pulmonary arteries, pulmonary veins, and mesenteric arteries from 12- to 24-h-old and 2-wk-old piglets (Figs. 1 and 2). Addition of similar volumes of Krebs solution saturated with $\mathrm{N}_{2}$ in place of $\mathrm{NO}$ or $\mathrm{CO}$ had no measurable effect on vessel tone. The vasorelaxant potency of $\mathrm{NO}$ was markedly greater than that of $\mathrm{CO}$ in all the vessels and in both age groups tested. In fact, the detectable threshold concentrations for the vasorelaxant effects of $\mathrm{CO}$ and $\mathrm{NO}$ were approximately $2 \times 10^{-5} \mathrm{M}$ and $5 \times 10^{-9} \mathrm{M}$, respectively. In addition, Figures 1 and 2 show that the relaxing effects of both $\mathrm{CO}$ and NO were completely inhibited by ODQ $\left(10^{-5} \mathrm{M}\right)$, a specific inhibitor of sGC. Pulmonary veins from either 12- to 24-h-old or 2-wk-old animals were the most-sensitive vessels $(p<0.05)$ to the relaxant effect of $\mathrm{CO}$ (relaxation at the maximum $\mathrm{CO}$ concentration tested was $37.4 \pm 2.4 \%$ and $33.5 \pm 4.1 \%$, respectively) compared with pulmonary ( $24.5 \pm$ $3.1 \%$ and $12 \pm 1.1 \%$, respectively) or mesenteric arteries ( $7.9 \pm 1.1 \%$ and $10.1 \pm 2.4 \%$, respectively). In the 12 - to 24-h-old piglets, NO-induced relaxation was significantly $(p<$ 0.05 ) smaller in pulmonary arteries (relaxation at the maximum NO concentration tested was $33.2 \pm 3.9 \%$ ) than in pulmonary veins $(71.8 \pm 3.6 \%)$ or mesenteric arteries $(73.1 \pm 3.0 \%)$, whereas in the 2-wk-old piglets, NO-induced relaxation was very similar in pulmonary arteries and veins (Fig. 2). Therefore, $\mathrm{CO}$-induced vasorelaxation clearly decreased with postnatal age in pulmonary arteries (Fig. $1 A$ ), whereas no change was observed in pulmonary veins or mesenteric arteries (Fig. 1, $B$ and $C$ ). In contrast, NO-induced relaxation augmented with postnatal age in pulmonary arteries (Fig. $2 A$ ), but was only weakly modified in pulmonary veins (Fig. $2 B$ ). Because both $\mathrm{CO}-$ and NO-induced relaxation were mediated by an activa-

Table 1. Contractile responses induced by U46619 $\left(10^{-7} \mathrm{M}\right)$ in piglet vessels

\begin{tabular}{lcccl}
\hline \multicolumn{1}{c}{ Vessel } & $n$ & $\begin{array}{c}\text { 12- to } \\
\text { 24-h-old } \\
\text { Tension (mg) }\end{array}$ & $n$ & $\begin{array}{c}\text { 2-wk-old } \\
\text { Tension (mg) }\end{array}$ \\
\hline Pulmonary artery & 60 & $471 \pm 26$ & 51 & $1163 \pm 67 \dagger$ \\
Pulmonary vein & 25 & $1108 \pm 110^{*}$ & 20 & $2913 \pm 257 \dagger$ \\
Mesenteric artery & 15 & $1059 \pm 91^{*}$ & 15 & $2583 \pm 298 \dagger$ \\
\hline
\end{tabular}

$* p<0.05$ vs pulmonary arteries, $\dagger p<0.05$ vs 12 - to 24-h-old. 

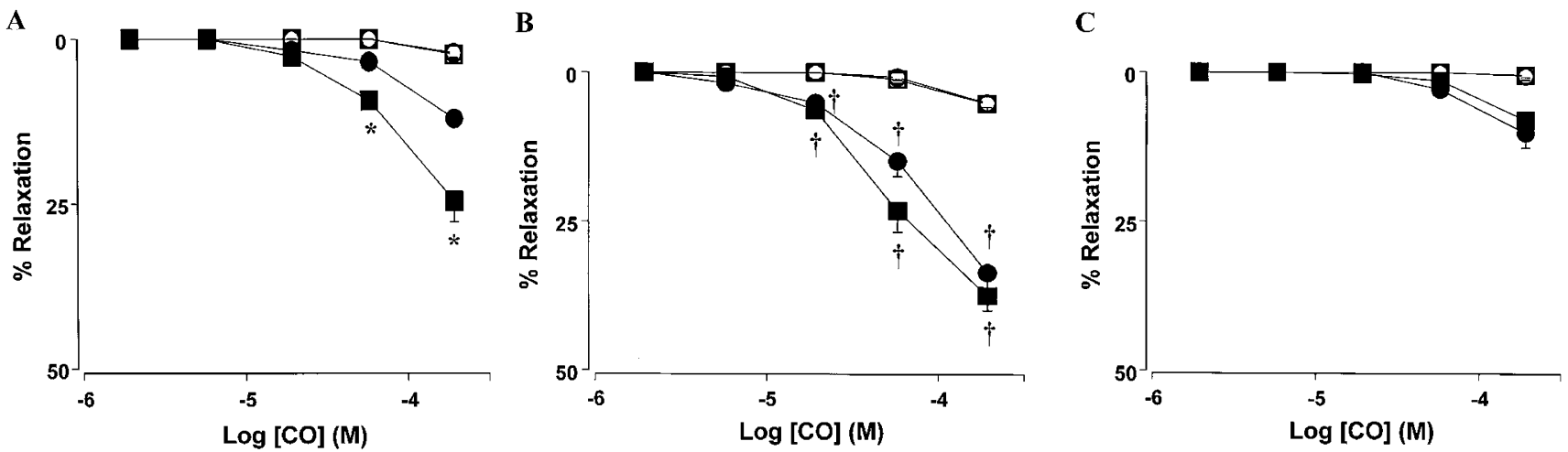

Figure 1. Concentration-dependent relaxant effects of $\mathrm{CO}$ in endothelium-denuded pulmonary arteries $(A)$, pulmonary veins $(B)$, and mesenteric arteries $(C)$ of 12- to 24-h-old $(\boldsymbol{\square}, \square)$ and 2-wk-old piglets $(\boldsymbol{\bullet}, \bigcirc)$. Changes in tension induced by $\mathrm{CO}$ are expressed as percentage of the contraction induced by $\mathrm{U} 46619\left(10^{-7}\right.$ $\mathrm{M})$. The experiments were performed in the absence (solid symbols) or presence (open symbols) of the sGC inhibitor ODQ $\left(10^{-5} \mathrm{M}\right)$. Each point represents the mean \pm SEM of $n$ arteries. Pulmonary arteries: $n=10$ (control, both groups of age), $n=6$ (+ODQ, both groups of age). Pulmonary veins: $n=10$ (control, both groups of age), $n=6$ ( + ODQ, both groups of age). Mesenteric arteries: $n=8$ (control, both groups of age), $n=6$ ( + ODQ, both groups of age). ${ }^{*} p<$ 0.0512 - to 24 -h-old $v s 2$-wk-old. $\dagger p<0.05$ pulmonary artery $v$ s pulmonary vein.
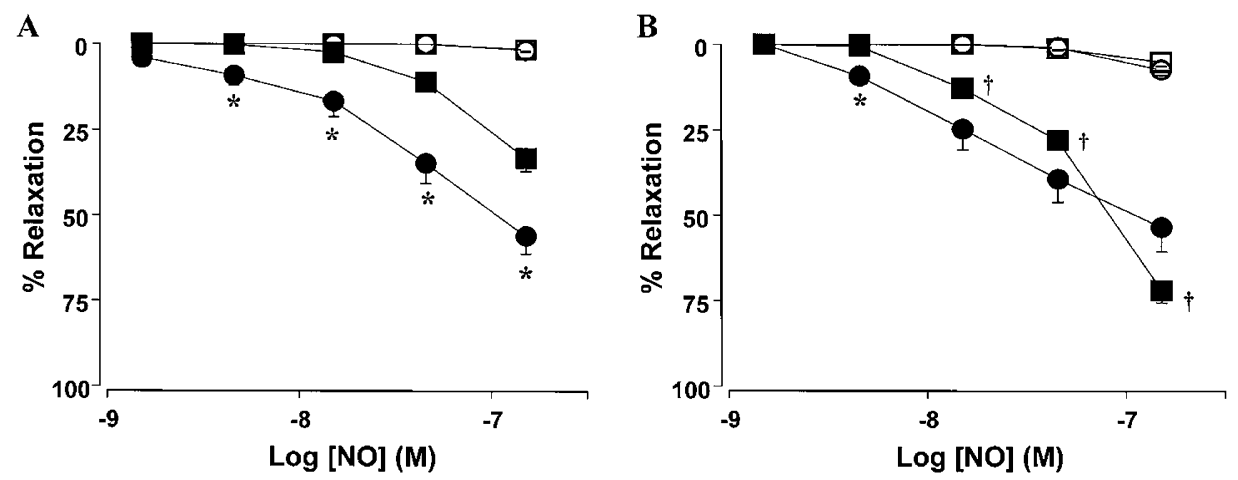

Figure 2. Concentration-dependent relaxant effects of NO in endothelium-denuded pulmonary arteries $(A)$ and pulmonary veins $(B)$ of 12 - to 24 -h-old $(\mathbf{\square}$, $\square)$ and 2-wk-old piglets $(\bullet, \bigcirc)$. Changes in tension induced by $\mathrm{CO}$ are expressed as a percentage of the contraction induced by $\mathrm{U} 46619\left(10^{-7} \mathrm{M}\right)$. The experiments were performed in the absence (solid symbols) or the presence (open symbols) of the sGC inhibitor ODQ $\left(10^{-5} \mathrm{M}\right)$. Each point represents the mean \pm SEM of $n$ arteries. Pulmonary arteries: $n=15$ (control, 12- to 24-h-old), $n=13$ (control, 2-wk-old), $n=6$ (+ODQ, both groups of age). Pulmonary veins: $n=10$ (control, both groups of age), $n=6$ ( + ODQ, both groups of age). ${ }^{*} p<0.0512$ - to 24-h-old $v s 2$-wk-old. $\dagger p<0.05$ pulmonary artery $v s$ pulmonary vein.

tion of sGC (as indicated by the inhibitory effects of ODQ), we analyzed the relaxant effect of the cGMP analog 8-bromocGMP. However, no significant differences were observed in the relaxant effects of 8-bromo-cGMP in endothelium-denuded pulmonary arteries from 12- to 24-h-old and 2-wk-old piglets (Fig. 3).

The role of endothelium in the vasodilator effects of $\mathrm{CO}$ and NO in pulmonary arteries from 2-wk-old piglets is shown in Figure 4. In endothelium-intact pulmonary artery rings, both $\mathrm{CO}$ and NO induced a relaxation that was similar to that induced in endothelium-free rings.

The endothelium-dependent relaxation induced by acetylcholine $\left(10^{-8}\right.$ to $\left.10^{-5} \mathrm{M}\right)$ increased with postnatal age $(p<$ 0.05 ) and was significantly greater in endothelium-intact pulmonary veins than in pulmonary arteries for both age groups (Fig. 5). The addition of the NO synthase inhibitor L-NAME $\left(10^{-4} \mathrm{M}\right)$ increased U46619-induced contractions by $18 \pm 2 \%$ (pulmonary arteries of 12- to 24-h-old piglets), $32 \pm 4 \%$ (pulmonary arteries of 2-wk-old piglets, $p<0.05$ versus 12 - to 24-h-old piglets), $3.4 \pm 0.7 \%$ (pulmonary veins of 12 - to 24-h-old piglets) and $7 \pm 1 \%$ (pulmonary veins of 2 -wk-old piglets, $p<0.05$ versus 12 - to 24 -h-old piglets). The increase of the U46619-induced contraction produced by L-NAME

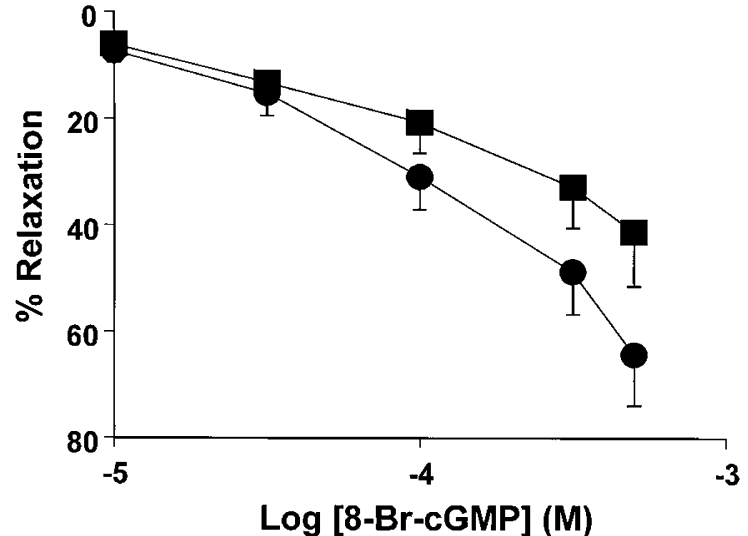

Figure 3. Concentration-dependent relaxant effects of the cGMP analog 8-bromo cGMP (8-Br-cGMP) in endothelium-denuded pulmonary arteries of 12- to 24-h-old $(\boldsymbol{\square}, n=6)$ and 2-wk-old piglets $(\mathbf{O}, n=6)$. Changes in tension induced by 8-bromo cGMP are expressed as a percentage of the contraction induced by $\mathrm{U} 46619\left(10^{-7} \mathrm{M}\right)$. Each point represents the mean \pm SEM of $n$ arteries.

reached a stable value after 20 min of exposure. Acetylcholineinduced relaxation was strongly inhibited by L-NAME in both pulmonary arteries and veins (Fig. 5), which indicates that the 

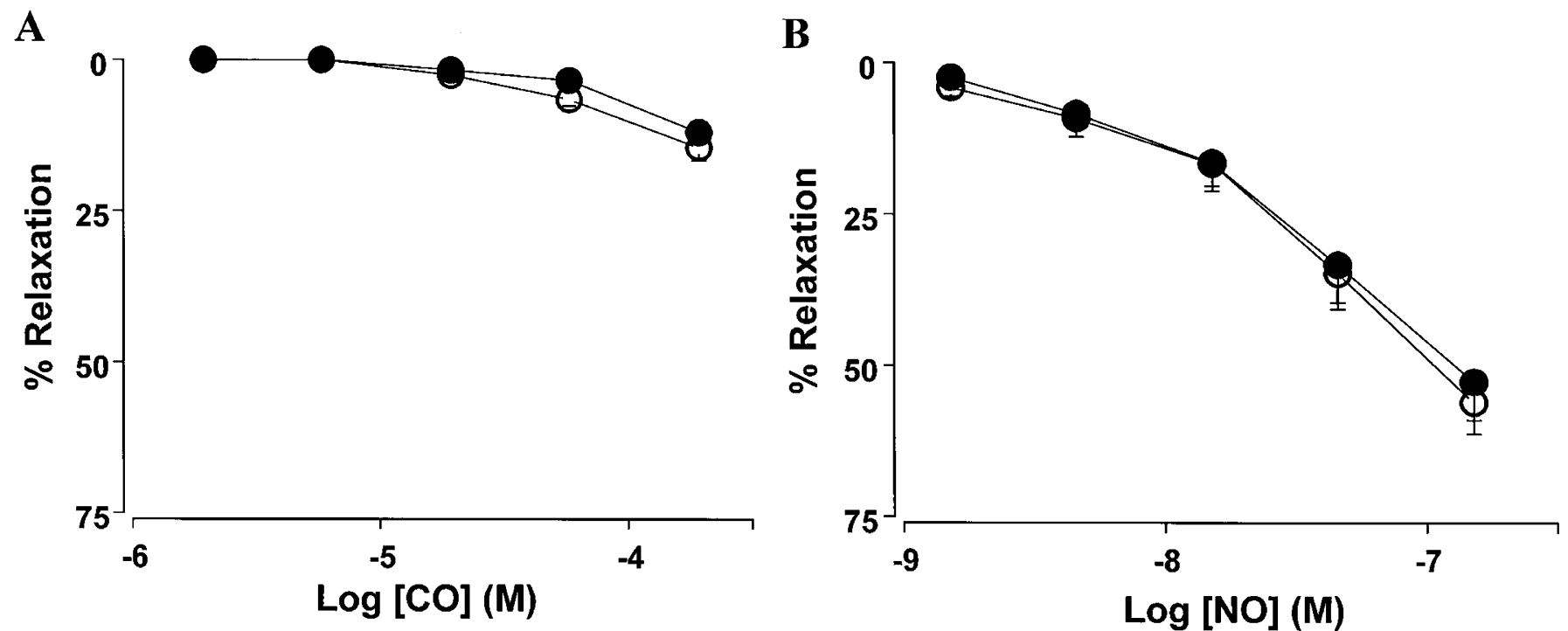

Figure 4. The effect of endothelium presence on $(A) \mathrm{CO}$ - and $(B)$ NO-induced vasorelaxation in 2-wk-old piglet pulmonary arteries. Arteries with endothelium $\left(\mathrm{O}, n=8\right.$ for both $\mathrm{CO}$ and NO experiments) and without endothelium $\left(\boldsymbol{\Theta}, n=13\right.$ for both $\mathrm{CO}$ and NO experiments) were precontracted with $\mathrm{U} 46619$ (10 ${ }^{-7}$ $\mathrm{M})$. Changes in tension induced by $\mathrm{CO}$ or NO are expressed as percentage of the contraction induced by $\mathrm{U} 46619\left(10^{-7} \mathrm{M}\right)$. Each point represents the mean \pm SEM of $n$ vessels.

A

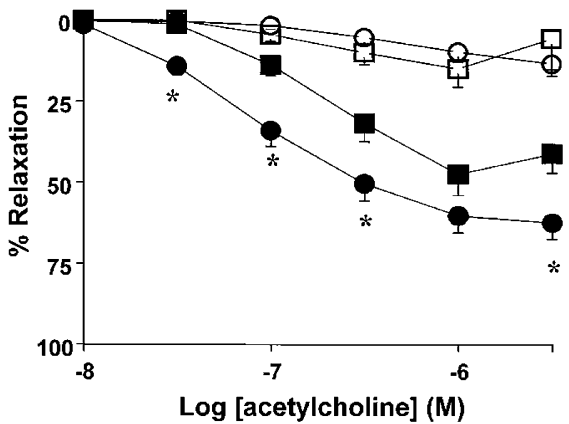

B

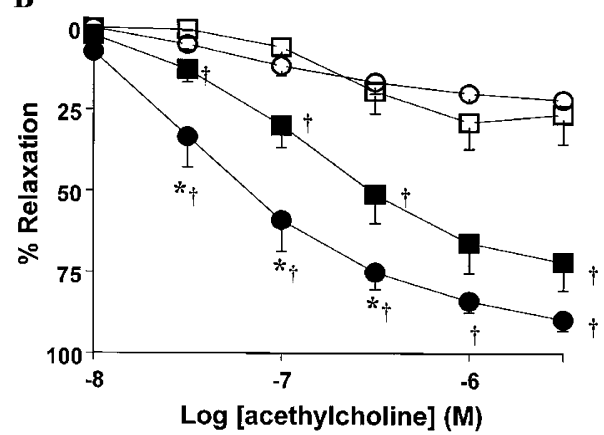

Figure 5. Concentration-dependent relaxant effects of acetylcholine in endothelium-intact pulmonary arteries $(A)$ and pulmonary veins $(B)$ of $12-$ to $24-\mathrm{h}$-old $(\boldsymbol{\square}, \square)$ and 2-wk-old piglets $(\mathbf{O}, \bigcirc)$. Changes in tension induced by acetylcholine are expressed as percentage of the contraction induced by $\mathrm{U}_{46619}\left(10^{-7} \mathrm{M}\right)$. The experiments were performed in the absence (solid symbols) or the presence (open symbols) of the NO synthase inhibitor L-NAME (10 $\left.{ }^{-4} \mathrm{M}\right)$. Each point represents the mean \pm SEM of $n$ arteries. Pulmonary arteries: $n=11$ (control, 12- to 24-h-old), $n=10$ (control, 2-wk-old), $n=6$ ( + L-NAME, both groups of age). Pulmonary veins: $n=10$ (control, 12- to 24-h-old), $n=11$ (control, 2-wk-old), $n=6$ (+L-NAME, both groups of age). ${ }^{*} p<0.05$ newborn $v s 2$-wk. $\dagger p<0.05$ pulmonary artery $v s$ pulmonary vein.

endothelium-dependent relaxation is mediated mainly by the release of NO from the endothelial cells.

In endothelium-intact pulmonary arteries from 2-wk-old piglets, changing the bubbling gas mixture from $95 \% \mathrm{O}_{2}\left(\mathrm{Po}_{2}\right.$, $86 \pm 0.62 \mathrm{kPa})$ to $0 \% \mathrm{O}_{2}\left(\mathrm{Po}_{2}, 4.51 \pm 0.03 \mathrm{kPa}\right)$ or $21 \% \mathrm{O}_{2}$ $\left(\mathrm{Po}_{2}, 19.32 \pm 0.17 \mathrm{kPa}\right)$ had no significant effect on basal tone. Furthermore, these different $\mathrm{PO}_{2}$ values in the organ chamber did not affect NO-induced vasorelaxation (Fig. 6).

Addition of the superoxide scavenger SOD $(100 \mathrm{U} / \mathrm{mL})$ had no significant effect on U46619-induced contractions in endothelium-denuded pulmonary arteries. Furthermore, the vasorelaxant response to $\mathrm{CO}$ in SOD-treated arteries from 2-wk-old piglets was similar to that in untreated controls (not shown). However, the response to NO was significantly increased in pulmonary arteries from 2-wk-old (Fig. 7B) but not 12- to 24-h-old piglets (Fig. 7A).

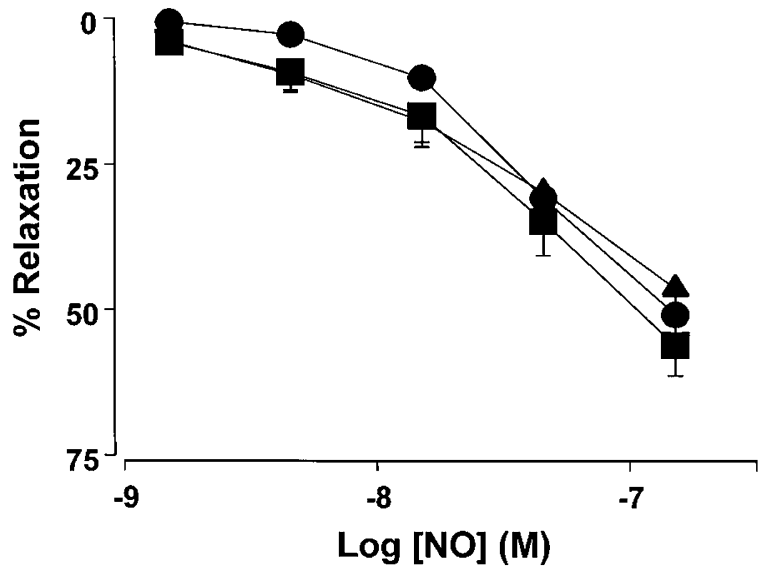

Figure 6. Effects of oxygen concentration on NO-induced vasorelaxation in 2 -wk-old piglet pulmonary arteries. Organ chambers were bubbled with $0 \%$ $(\bullet, n=7), 21 \%(\boldsymbol{\Lambda}, n=9)$ or $95 \% \mathrm{O}_{2}(\boldsymbol{\square}, n=13)$. Changes in tension induced by $\mathrm{NO}$ are expressed as percentage of the contraction induced by U46619 $\left(10^{-7} \mathrm{M}\right)$. Each point represents the mean \pm SEM of $n$ arteries. 
A

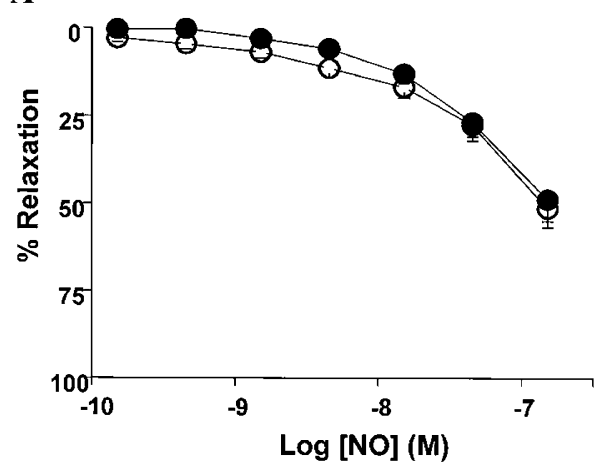

B

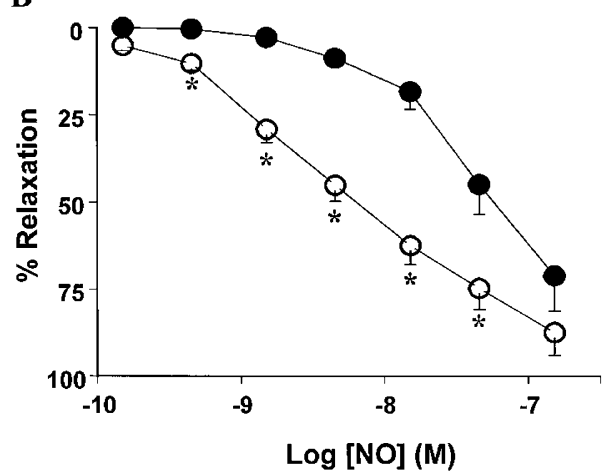

Figure 7. Effects of SOD on NO-induced vasorelaxation in 12- to 24-h-old $(A)$ and 2-wk-old $(B)$ piglet pulmonary arteries. The experiments were performed in the absence $(-)$ or the presence $(\bigcirc)$ of SOD $(100 \mathrm{U} / \mathrm{mL})$. Changes in tension induced by NO are expressed as percentage of the contraction induced by U46619 $\left(10^{-7} \mathrm{M}\right)$ Each point represents the mean $\pm \mathrm{SEM}$ of $n$ arteries. $N=15$ (control, 12- to 24-h-old), $n=13$ (control, 2-wk-old), $n=6$ ( $+\mathrm{SOD}, 12$ - to 24-h-old), $n=11$ ( + SOD, 2-wk-old). ${ }^{*} p<0.05$ SOD-treated arteries $v s$ controls.

\section{DISCUSSION}

The present study demonstrated that $\mathrm{CO}$ relaxed vessels of 12- to 24-h-old and 2-wk-old piglets. Moreover, CO-induced vasorelaxation was more marked in pulmonary arteries in the first day of extrauterine life than that of 2-wk-old piglets and in pulmonary veins than in pulmonary or mesenteric arteries. Moreover, the vasorelaxant effect of $\mathrm{CO}$ was endotheliumindependent but abolished by specific inhibition of sGC. However, when compared with $\mathrm{NO}, \mathrm{CO}$ was a weak vasorelaxant, the relative potency of $\mathrm{CO}$ to $\mathrm{NO}$ being approximately 1:1000. In contrast to $\mathrm{CO}, \mathrm{NO}$ - and acetylcholine-induced vasorelaxation increased with postnatal age in piglet pulmonary arteries. Changes in extracellular oxygen concentration did not affect NO-induced vasorelaxation. Finally, in 2-wk-old pulmonary arteries, SOD improved the response to $\mathrm{NO}$ but not to $\mathrm{CO}$, whereas in 12- to 24-h-old pulmonary arteries, SOD was without effect on NO- induced vasorelaxation.

Several mechanisms have been proposed to explain the vasorelaxation induced by $\mathrm{CO}$ and $\mathrm{NO}$ (17) including not only activation of $\mathrm{sGC}(11)$ but also stimulation of $\mathrm{K}^{+}$channels (17, 27 ) or inhibition of the cytochrome P450 monooxygenase (28, 29). Hussain et al. (30) have shown that ODQ completely abolished relaxation of rabbit aortic rings induced by $\mathrm{CO}$, whereas only a partial attenuation of NO-induced relaxation was achieved. In contrast, we found that ODQ completely abolished CO- and NO-induced relaxation, indicating that sGC was responsible for the effects of both vasorelaxants in piglet neonatal vessels. Similar findings have been reported for NOinduced vasorelaxation in pulmonary arteries of newborn lambs (31). Moreover, we have previously demonstrated that the NO donor sodium nitroprusside increased cGMP levels and relaxed pulmonary arteries from 2 -wk-old piglets but neither $\mathrm{K}^{+}$channels nor the membrane $\mathrm{Na}^{+} / \mathrm{K}^{+}$ATPase were involved in these effects (24). However, in the isolated lamb ductus arteriosus, CO-induced vasorelaxation was not accompanied by a significant accumulation of cGMP (29).

$\mathrm{CO}$ produced a weak vasorelaxant effect, particularly when compared with NO. Similar results have been previously reported in several vascular beds (11). Inhaled CO in concentrations up to $1000 \mathrm{ppm}$ in adult rats and fetal lambs had no effect
$(32,33)$, whereas markedly lower concentrations of inhaled NO $(<5 \mathrm{ppm})$ are required to produce significant pulmonary vasorelaxation $(33,34)$. Differences in the activation of sGC have been proposed to explain the distinct vasorelaxant potency of $\mathrm{CO}$ and $\mathrm{NO}(35)$, i.e. enzymatic activity of $\mathrm{sGC}$ is increased approximately 100 - to 200 -fold by NO, but only by 4- to 5-fold by $\mathrm{CO}$ (35). The activation of sGC by NO appears to be a complex process. First, NO binds to the heme group of the enzyme forming a hexacoordinate complex, which then converts to a pentacoordinate nitrosyl-heme (35-37). CO also forms a complex with the heme moiety of sGC, but unlike NO, only the six-coordinate complex is formed, which results in a weak activation of the enzyme (35-37). On the other hand, nanomolar concentrations of NO competitively prevent the binding of $\mathrm{CO}$ to the heme group of the $\mathrm{sGC}$, thus reducing its vascular effect (37). The vasoconstrictor effect of L-NAME in our preparations indicates that NO is released from the endothelium under basal conditions. However, the presence of endothelium did not modify the relaxant effects of $\mathrm{CO}$, indicating that basal release of $\mathrm{NO}$ from the endothelium does not modulate the relaxant effect of $\mathrm{CO}$ in piglet pulmonary arteries.

Although blood vessels produce CO (38), whether this CO reaches a sufficient concentration to relax vascular smooth muscle remains unclear. The nonselective HO-2 inhibitor tin protoporphyrin IX has been shown to inhibit the endotheliumdependent relaxation induced by acetylcholine after inhibition of NO synthesis, suggesting an involvement of endotheliumderived $\mathrm{CO}$ (6). We found that the endothelium-dependent relaxation produced by acetylcholine was strongly reduced by the NO synthase inhibitor L-NAME, indicating that it is mainly mediated by the release of NO. This result, together with the low vasodilator potency of $\mathrm{CO}$, suggests that a possible role for $\mathrm{CO}$ as an endothelium-dependent vasodilator in neonatal pulmonary vessels would be small if any. However, this is an in vitro study, and, thus, extrapolation of the present results to in vivo vascular responses to $\mathrm{CO}$ and $\mathrm{NO}$ should be done with caution. Moreover, it is unclear whether endogenously generated $\mathrm{CO}$ has a vascular effect similar to that of exogenously applied $\mathrm{CO}$. In fact, the physiologic concentrations of $\mathrm{CO}$ and $\mathrm{NO}$ in the immediate vicinity of vascular smooth muscle cells 
in vivo are unknown (17). Nevertheless, studies in brain tissues (39) indicate that the concentrations of $\mathrm{CO}$ produced in vivo $(1-200 \mu \mathrm{M})$ are lower than those producing vascular relaxation in the present experiments. In contrast, these concentrations of $\mathrm{CO}$ produced significant relaxation in other vascular rings (11, 17).

Superoxide anions produced in several metabolic reactions inactivate $\mathrm{NO}$, forming peroxynitrite (25). In fact, the superoxide scavenger SOD significantly increased the in vitro relaxant activity of NO (40). Moreover, the combination of high doses of inhaled $\mathrm{NO}(100 \mathrm{ppm})$ and $90 \% \mathrm{O}_{2}$ caused oxidative damage in mechanically ventilated newborn piglets, which was mitigated by the use of recombinant human SOD (41). Therefore, the use of SOD might be suggested as a way of reducing the toxicity and augmenting the response to inhaled $\mathrm{NO}$, which may lead to novel clinical strategies to improve the treatment of neonatal pulmonary hypertension. Even when $\mathrm{CO}$ shares with $\mathrm{NO}$ some properties (i.e. activation of $\mathrm{sGC}$ and reaction with $\mathrm{Hb}$ ), $\mathrm{CO}$ is not a free radical and is not expected to react with superoxide. Accordingly, the antioxidant enzyme SOD had no effect on CO-induced vasorelaxation but improved NO-induced vasorelaxation (but only in the 2-wk-old animals).

Fetal pulmonary arteries are exposed to a relatively hypoxic environment, and then at birth they are exposed to $21 \% \mathrm{O}_{2}$. It is well known that acetylcholine-induced endogenous production of NO is markedly influenced by the oxygen tension in the organ chamber $(42,43)$. Theoretically, extreme hyperoxia can destroy NO by an increased formation of superoxide anions. Additionally, an increased oxidative stress can produce oxidation of the heme group of sGC, resulting in loss of enzyme activity $(25,37)$. However, no differences in exogenous NOinduced vasorelaxation were observed when the organ chambers were bubbled with $0 \%, 21 \%$, or $95 \% \mathrm{O}_{2}$. This suggests that high $\mathrm{O}_{2}$ concentrations did not produce the effects mentioned above (i.e. increase in superoxide anions or oxidation of the heme group of sGC) to an extent sufficient to reduce NO-induced vasorelaxation in our experiments.

Pulmonary veins are the major site of action of a number of vasoactive factors in different animal species and at different ages $(44,45)$. In newborn piglets, we observed that the response not only to exogenous or endogenous NO but also to exogenous $\mathrm{CO}$ was greater in pulmonary veins than in pulmonary arteries. This difference was maintained in the 2-wk-old piglets for the response to $\mathrm{CO}$ but not for NO. It has been demonstrated that basal concentrations, as well as the increase of cGMP in response to NO, were greater in pulmonary veins than in pulmonary arteries of newborn lambs (45). This could be accounted for, at least partly, by a higher activity of cGMP-specific phosphodiesterases, which produced faster hydrolysis and inactivation of cGMP in pulmonary arteries when compared with pulmonary veins (46).

In the present work, CO-induced relaxation decreased in pulmonary arteries with postnatal age, whereas the cell membrane-permeable analog of cGMP 8-bromo-cGMP produced a similar degree of relaxation in pulmonary arteries from both groups of age. Because 8-bromo-cGMP is very resistant to being hydrolyzed by phosphodiesterases, the age-dependent changes in the effects of $\mathrm{CO}$ might be also attributed to an increase in phosphodiesterase activity during the first days of extrauterine life as described in ovine and mouse lung (47). In contrast, the vasorelaxant response to endogenous $\mathrm{NO}$ increased with age in piglet (48) and present results), sheep (49), and rabbit pulmonary arteries (43). We also found an agedependent increase in the vasodilator response to exogenous NO in piglet pulmonary arteries, suggesting that the agedependent increase to endogenous NO is not only related to increased synthesis but also to an increased action or decreased metabolism of NO. Morecroft and MacLean (43) found that SOD potentiated acetylcholine-induced relaxation in pulmonary arteries from newborn but not from adult rabbits and suggested that the age-dependent increase in the response to endogenous NO was because of an increased accumulation of superoxide in the newborn animals. In contrast, and unexpectedly, SOD did not affect NO-induced relaxation in pulmonary arteries from 12- to 24-h-old piglets but potentiated the relaxant response to $\mathrm{NO}$ in mesenteric arteries from these animals (not shown) and in pulmonary arteries from 2-wk-old piglets. Even when the reasons for the lack of effect of SOD in 12- to 24-h-old pulmonary arteries are unclear, several theoretical explanations can be raised: 1) reduced ability of exogenous SOD to penetrate cell membranes, 2) reduced endogenous superoxide production or increased endogenous antioxidant activity, and 3) differential effects of the peroxynitrites. Further studies involving the use of low-molecular-weight membranepermeant compounds that exhibit SOD-like activity (50) and SOD inhibitors are necessary to elucidate this point. Additionally, the use of SOD from a nonporcine source could have limited its effect in our experiments. However, bovine and porcine SOD have a high degree of homology in their sequences and similar kinetic variables (51) as to reasonably assume identical in vitro activity.

In conclusion, $\mathrm{CO}$ produced vasorelaxation in neonatal vessels by activation of $\mathrm{sGC}$, but its vasorelaxant potency is markedly reduced compared with NO. Both CO- and NOinduced relaxation was greater in pulmonary veins than in pulmonary arteries. However, whereas NO-induced relaxation in pulmonary arteries was augmented with postnatal age, that induced by $\mathrm{CO}$ decreased. Changes in extracellular $\mathrm{O}_{2}$ concentration did not alter the pulmonary vascular response to NO. In contrast, the presence of SOD improved the response to NO in 2-wk-old piglets, indicating that oxidant activity limits the vasorelaxant response to $\mathrm{NO}$ but not to $\mathrm{CO}$. The functional significance of endogenous $\mathrm{CO}$ has not been established to date, but it might play, together with NO, a modulatory role in the regulation of vascular contractile responses. However, if the response to exogenous $\mathrm{CO}$ reflects the capacity of this gas to relax in vivo neonatal pulmonary vessels, its direct participation in the control of pulmonary vascular tone seems unlikely.

Acknowledgment. The authors thank C. Rivas for excellent technical assistance.

\section{REFERENCES}

1. Barnes PJ, Liu SF 1995 Regulation of pulmonary vascular tone. Pharmacol Rev 47:87-131 
2. Marks GS, Brien JF, Nakatsu K, McLaughlin BE 1991 Does carbon monoxide have a physiological function? Trends Pharmacol Sci 12:185-188

3. Maines MD 1997 The heme oxygenase system: a regulator of second messenger gases. Annu Rev Pharmacol Toxicol 37:517-554

4. Brune B, Ullrich V 1987 Inhibition of platelet aggregation by carbon monoxide is mediated by activation of guanylate cyclase. Mol Pharmacol 32:497-504

5. Kharitonov VG, Sharma VS, Pilz RB, Magde D, Koesling D 1995 Basis of guanylate cyclase activation by carbon monoxide. Proc Natl Acad Sci USA 92:2568-2571

6. Zakhary R, Gaine SP, Dinerman JL, Ruat M, Flavahan NA, Snyder SH 1996 Heme oxygenase 2: endothelial and neuronal localization and role in endothelium-dependent relaxation. Proc Natl Acad Sci USA 93:795-798

7. Okinaga S, Takahashi K, Takeda K, Yoshizawa M, Fujita H, Sasaki H, Shibahara S 1996 Regulation of human heme oxygenase-1 gene expression under thermal stress. Blood 87:5074-5084

8. Cantoni L, Rossi C, Rizzardini M, Gardina M, Ghezzi P 1991 Interleukin-1 and tumor necrosis factor induce hepatic heme oxygenase. Biochem J 279:891-894

9. Willis D, Moore AR, Frederick R, Willoughby DA 1996 Heme oxygenase: a novel target for the modulation of the inflammatory response. Nat Med 2:87-90

10. Duke HN, Killick EM 1952 Pulmonary vasomotor responses of isolated perfused cat lungs to anoxia J Physiol (Lond) 117:303-316

11. Furchgott RF, Jothianandan D 1991 Endothelium-dependent and -independent vasodilation involving cyclic GMP: relaxation induced by nitric oxide, carbon monoxide and light. Blood Vessels 28:52-61

12. Brian Jr JE, Heistad DD, Faraci FM 1994 Effect of carbon monoxide on rabbi cerebral arteries. Stroke 25:639-643

13. Wang R, Wang Z, Wu L 1997 Carbon monoxide-induced vasorelaxation and the underlying mechanisms. Br J Pharmacol 121:927-934

14. Suematsu M, Goda N, Sano T, Kashiwagi S, Egawa T, Shinoda Y, Ishimura Y 1995 Carbon monoxide: an endogenous modulator of sinusoidal tone in the perfused rat liver. J Clin Invest 96:2431-2437

15. Sammut IA, Foresti R, Clark JE, Exon DJ, Vesely MJ, Sarathchandra P, Green CJ, Motterlini R 1998 Carbon monoxide is a major contributor to the regulation of vascular tone in aortas expressing high levels of haeme oxygenase-1. Br J Pharmacol 125:1437-1444

16. Coceani F, Kelsey L, Seidlitz E, Marks GS, McLaughlin BE, Vreman HJ, Stevenson DK, Rabinovitch M, Ackerley C 1997 Carbon monoxide formation in the ductus arteriosus in the lamb: implications for the regulation of muscle tone. $\mathrm{Br} \mathrm{J}$ Pharmacol 120:599-608

17. Wang R 1998 Resurgence of carbon monoxide: an endogenous gaseous vasorelaxing factor. Can J Physiol Pharmacol 76:1-15

18. Haworth SG, Hislop AA 1981 Adaptation of the pulmonary circulation to extrauterine life in the pig and its relevance to the human infant. Cardiovasc Res 15:108-119

19. Perreault T, De Marte J 1993 Maturational changes in endothelium-derived relax ations in newborn piglet circulation. Am J Physiol 264:H302-H309

20. Ziegler JW, Ivy DD, Kinsella JP, Abman SH 1995 The role of nitric oxide, endothelin, and prostaglandins in the transition of the pulmonary circulation. Clin Perinatol 22:387-403

21. Yao TC, Stevenson DK 1995 Advances in the diagnosis and treatment of neonatal hyperbilirubinemia. Clin Perinatol 22:741-758

22. Pérez-Vizcaíno F, Villamor E, Moro M, Tamargo J 1996 Lack of endotoxin-induced hyporesponsiveness to U46619 in isolated neonatal porcine pulmonary but not mesenteric arteries. J Vasc Res 33:249-257

23. Villamor E, Pérez-Vizcaíno F, Moro M, Tamargo J 1996 Effects of group B streptococcus on the responses to U46619, endothelin and noradrenaline in isolated intrapulmonary and mesenteric arteries of piglets. Pediatr Res 40:827-833

24. Perez-Vizcaino F, Villamor E, Duarte J, Tamargo J 1997 Involvement of protein kinase $\mathrm{C}$ in reduced relaxant responses to the $\mathrm{NO} /$ cyclic GMP pathway in piglet pulmonary arteries contracted by the thromboxane $\mathrm{A}_{2}$-mimetic U46619. Br J Pharmacol 121:1323-1333

25. Beckman JS, Koppenol WH 1996 Nitric oxide, superoxide, and peroxynitrite: the good, the bad, and the ugly. Am J Physiol 271:C1424-C1437

26. Brunner F, Schmidt K, Nielsen EB, Mayer B 1996 Novel guanylyl cyclase inhibitor potently inhibits cyclic GMP accumulation in endothelial cells and relaxation of bovine pulmonary artery. J Pharmacol Exp Ther 277:48-53

27. Bolotina VM, Najibi S, Palacino JJ, Pagano PJ, Cohen RA 1994 Nitric oxide directly activates calcium-dependent potassium channels in vascular smooth muscle. Nature 368:850-853

28. Coceani F, Breen CA, Lees JG, Falck JR, Olley PM 1988 Further evidence implicating a cytochrome P-450-mediated reaction in the contractile tension of the lamb ductus arteriosus. Circ Res 62:471-477
29. Coceani F, Kelsey L, Seidlitz E 1996 Carbon monoxide-induced relaxation of the ductus arteriosus in the lamb: evidence against the prime role of guanylyl cyclase. Br J Pharmacol 118:1689-1696

30. Hussain AS, Marks GS, Brien JF, Nakatsu K 1997 The soluble guanylyl cyclase inhibitor $1 \mathrm{H}-[1,2,4]$ oxadiazolo[4,3-alpha]quinoxalin-1-one (ODQ) inhibits relaxation of rabbit aortic rings induced by carbon monoxide, nitric oxide, and glyceryl trinitrate. Can J Physiol Pharmacol 75:1034-1037

31. Gao Y, Tolsa JF, Raj JU 1998 Heterogeneity in endothelium-derived nitric oxidemediated relaxation of different sized pulmonary arteries of newborn lambs. Pediatr Res 44:723-729

32. Cantrell JM, Tucker A 1996 Low-dose carbon monoxide does not reduce vasoconstriction in isolated rat lungs. Exp Lung Res 22:21-32

33. Grover TR, Rairigh RL, Abman SH, Kinsella JP 1999 Pulmonary vascular effects of inhaled carbon monoxide on the ovine transitional circulation. Pediatr Res 45:303A(abstr)

34. Rich GF, Roos CM, Anderson SM, Urich DC, Daugherty MO, Johns RA 1993 Inhaled nitric oxide: dose response and the effects of blood in the isolated rat lung. J Appl Physiol 75:1278-1284

35. Deinum G, Stone JR, Babcock GT, Marletta MA 1996 Binding of nitric oxide and carbon monoxide to soluble guanylate cyclase as observed with resonance Raman spectroscopy. Biochemistry 35:1540-1547

36. Stone JR, Marletta MA 1994 Soluble guanylate cyclase from bovine lung: activation with nitric oxide and carbon monoxide and spectral characterization of the ferrous and ferric states. Biochemistry 33:5636-5640

37. Hobbs AJ 1997 Soluble guanylate cyclase: the forgotten sibling. Trends Pharmacol Sci 18:484-491

38. Grundemar L, Johansson MB, Ekelund M, Hogestatt ED 1995 Haem oxygenase activity in blood vessel homogenates as measured by carbon monoxide production. Acta Physiol Scand 153:203-204

39. Nathanson JA, Scavone C, Scanlon C, McKee M 1995 The cellular $\mathrm{Na}^{+}$pump as a site of action for carbon monoxide and glutamate: a mechanism for long-term modulation of cellular activity. Neuron 14:781-794

40. Rubanyi GM, Vanhoutte PM 1986 Superoxide anions and hyperoxia inactivate endothelium-derived relaxing factor. Am J Physiol 250:H822-H827

41. Robbins CG, Horowitz S, Merritt TA, Kheiter A, Tierney J, Narula P, Davis JM 1997 Recombinant human superoxide dismutase reduces lung injury caused by inhaled nitric oxide and hyperoxia. Am J Physiol 272:L903-L907

42. Furchgott RF, Zawadzki JV 1980 The obligatory role of endothelial cells in the relaxation of arterial smooth muscle by acetylcholine. Nature 288:373-376

43. Morecroft I, MacLean MR 1998 Developmental changes in endothelium-dependent vasodilation and the influence of superoxide anions in perinatal rabbit pulmonary arteries. Br J Pharmacol 125:1585-1593

44. Raj JU, Hillyard R, Kaapa P, Gropper M, Anderson J 1990 Pulmonary arterial and venous constriction during hypoxia in 3- to 5-wk-old and adult ferrets. J Appl Physiol 69:2183-2189

45. Gao Y, Zhou H, Raj JU 1995 Endothelium-derived nitric oxide plays a larger role in pulmonary veins than in arteries of newborn lambs. Circ Res 76:559-565

46. Okogbule-Wonodi AC, Ibe BO, Yue BW, Hsu S, Raj JU 1998 Phosphodiesterase activity in intrapulmonary arteries and veins of perinatal lambs. Mol Genet Metab 65:229-237

47. Hanson KA, Burns F, Rybalkin SD, Miller JW, Beavo J, Clarke WR 1998 Developmental changes in lung cGMP phosphodiesterase-5 activity, protein, and message. Am J Respir Crit Care Med 158:279-288

48. Liu SF, Hislop AA, Haworth SG, Barnes PJ 1992 Developmental changes in endothelium-dependent pulmonary vasodilatation in pigs. Br J Pharmacol 106:324330

49. Steinhorn RH, Morin 3d FC, Gugino SF, Giese EC, Russell JA 1993 Developmental differences in endothelium-dependent responses in isolated ovine pulmonary arteries and veins. Am J Physiol 264:H2162-H2167

50. MacKenzie A, Martin W 1998 Loss of endothelium-derived nitric oxide in rabbi aorta by oxidant stress: restoration by superoxide dismutase mimetics. Br J Pharmacol 124:719-728

51. Desideri A, Falconi M, Polticelli F, Bolognesi M, Djinovic K, Rotilio G 1992 Evolutionary conservativeness of electric field in the $\mathrm{Cu}, \mathrm{Zn}$ superoxide dismutase active site: evidence for coordinated mutation of charged amino acid residues. J Mol Biol 223:337-342 